\title{
Nox4 has a crucial role in uric acid-induced oxidative stress and apoptosis in renal tubular cells
}

\author{
ZHUOHANG LI ${ }^{1,2^{*}}$, YIYU SHENG ${ }^{1,2 *}$, CHENG LIU ${ }^{1 *}$, \\ KUIQING LI ${ }^{1}$, XIN HUANG ${ }^{1}$, JIAN HUANG ${ }^{1}$ and KEWEI XU ${ }^{1,3}$ \\ ${ }^{1}$ Department of Urology; ${ }^{2}$ Guangdong Provincial Key Laboratory of Malignant Tumor Epigenetics and Gene Regulation; \\ ${ }^{3}$ Department of Boji Healthcare Center, Sun Yat-sen Memorial Hospital, \\ Sun Yat-sen University, Guangzhou, Guangdong 510120, P.R. China
}

Received March 20, 2015; Accepted March 8, 2016

DOI: $10.3892 / \mathrm{mmr} .2016 .5083$

\begin{abstract}
The purpose of the present study was to evaluate the effects of uric acid in promoting tubular cell apoptosis and verify the role of nicotinamide adenine dinucleotide phosphate oxidase 4 (Nox4)-induced oxidative stress in this process. HK-2 cells were used as a human proximal tubular cell model and co-cultured with various concentrations of uric acid with or without pre-treatment with the Nox4 inhibitor diphenylene iodonium (DPI). The apoptotic rate and the amount of reactive oxygen species (ROS) were examined by flow cytometry. Furthermore, levels of Nox4, phosphorylated (p)-P38, p-extracellular signal-regulated kinase (ERK), B-cell lymphoma 2 (Bcl-2) and Bcl-2-extra large (Bax) were detected by western blot analysis. The results showed that treatment with uric acid decreased HK-2 cell viability and promoted apoptosis in a dose-dependent manner. This was paralleled with an upregulation of Nox4 as well as ROS overproduction, which activated the phosphorylation of P38/ERK and caused an imbalance of Bax/Bcl-2 in HK-2 cells. Of note, inhibition of Nox4 with DPI prevented uric acid-induced cell injury by suppressing ROS generation and P38/ERK activation. In conclusion, it was demonstrated that elevated uric acid promoted ROS-induced tubular cell apoptosis by upregulating Nox4 expression. The present study therefore provided possible mechanisms and a potential therapeutic target of uric acid-induced chronic kidney disease.
\end{abstract}

Correspondence to: Professor Kewei $\mathrm{Xu}$, Department of Urology, Sun Yat-sen Memorial Hospital, Sun Yat-sen University, 107 Yanjiangxi Road, Guangzhou, Guangdong 510120, P.R. China E-mail: xkw2005@163.com

*Contributed equally

Key words: nicotinamide adenine dinucleotide phosphate oxidase, uric acid, proximal tubular cell, apoptosis, reactive oxygen species

\section{Introduction}

Hyperuricemia is a common metabolic disorder. Recent studies showed that it is also an independent risk factor for chronic kidney disease $(1,2)$. Elevated serum uric acid (UA) levels not only decrease the glomerular filtration rate, but also induce tubulointerstitial injury. However, the underlying mechanisms have remained to be fully elucidated $(2,3)$. Previous studies indicated that high levels of UA promoted reactive oxygen species (ROS) generation to increase oxidative stress in several cell types, including mesangial cells, adipocytes and vascular smooth muscle cells (4-6). ROS are considered to be crucial mediators of cell apoptosis (7-9). In kidney disease, apoptosis is one of the main causes of tubular cell loss (10). Therefore, the present study hypothesized that high levels of UA induce oxidative stress within renal tubular cells and lead to apoptosis, which eventually causes renal dysfunction.

Nicotinamide adenine dinucleotide phosphate oxidase 4 (Nox4) is the predominant Nox in the kidney $(8,11)$. It generates ROS by transferring an electron to molecular oxygen. Nox4-derived ROS have an important role in cell signaling as secondary messengers, mediating numerous biological processes, including cell apoptosis $(7,8)$. However, it has remained elusive whether UA-mediated Nox4 expression represents an endogenous source of ROS in tubular cells.

The present study confirmed that elevated UA promotes apoptosis by upregulating the expression of Nox 4 in renal tubular cells. In addition, the underlying mechanisms were examined, including ROS generation and the activation of extracellular signal-regulated kinase (ERK)1/2 as well as P38.

\section{Materials and methods}

Reagents. Dulbecco's modified Eagle's medium (DMEM)/F-12, fetal bovine serum (FBS), penicillin and streptomycin were obtained from Gibco (Thermo Fisher Scientific, Inc., Waltham, MA, USA). 2',7'-dichlorodihydrofluorescein diacetate (DCFH-DA), diphenylene iodonium (DPI), bovine serum albumin (BSA) and uric acid were purchased from Sigma-Aldrich (St. Louis, MO, USA)Polyclonal rabbit anti-human Nox4 (cat.no. BS6796) was obtained from Bioworld Technology, Inc. (St. Louis Park, MN, USA). Monoclonal rabbit 
anti-human phosphorylated (p)-P38 (cat. no. 4631), p-ERK1/2 (cat. no. 4376), P38 (cat. no. 8690), ERK1/2 (cat. no. 4695), B-cell lymphoma 2 (Bcl-2; cat. no. 2870), Bcl-2-associated X protein (Bax; cat. no. 5023) and $\beta$-actin (cat. no. 4970) primary antibodies, and horseradish peroxidase-labeled goat anti-rabbit immunoglobulin G (IgG) secondary antibody (cat. no. 7074) were obtained from Cell Signaling Technology, Inc. (Danvers, MA, USA). A bicinchoninic acid (BCA) protein assay kit was obtained from Thermo Fisher Scientific. A polyvinylidene difluoride (PVDF) membrane and SuperECL Plus hypersensitivity luminous fluid were purchased from Millipore (Billerica, MA, USA). All chemical reagents were of analytical grade.

Cell culture and treatment. HK-2 cells were obtained from the American Type Culture Collection (Manassas, VA, USA). Cells were cultured at $37^{\circ} \mathrm{C}$ in a humidified atmosphere containing $5 \% \mathrm{CO}_{2}$ in DMEM/F-12, which contained $10 \%$ FBS, $100 \mathrm{IU} / \mathrm{ml}$ penicillin and $100 \mu \mathrm{g} / \mathrm{ml}$ streptomycin. When the cell density reached $70-80 \%$, the cells were maintained in serum-free medium overnight in order to synchronize the cell cycle and eliminate the influence of serum on cellular functions. HK-2 cells were then incubated with various concentrations of UA ( 4,8 or $16 \mathrm{mg} / \mathrm{dl})$ for 24,48 and $72 \mathrm{~h}$. To inhibit the function of Nox, $10 \mu \mathrm{M}$ DPI was applied for $30 \mathrm{~min}$ prior to incubation with UA. The negative control (NC) group was not treated with UA or DPI.

Cell viability assay. The cell viability/cytotoxicity was determined using a 3-(4,5-dimethyl-2-thiazolyl)-2, 5-diphenyl-2Htetrazolium bromide (MTT) assay). HK-2 cells were seeded into 96-well culture plates at the density of 2,000 cells per well and then treated with various concentrations of UA. After 24, 48 or $72 \mathrm{~h}$ of incubation, the assay was performed by adding $20 \mu \mathrm{l}$ of MTT solution $[5 \mathrm{mg} / \mathrm{ml}$ in phosphate-buffered saline (PBS); Sigma-Aldrich] to each well, followed by incubation for $4 \mathrm{~h}$. Subsequently, $100 \mu \mathrm{l}$ dimethyl sulfoxide (DMSO; Sigma-Aldrich) was added to the culture medium in each well to dissolve the formazan crystals and the absorbance of each well was measured at $492 \mathrm{~nm}$ using a SpectraMax M5 plate reader (Molecular Devices, LLC, Sunnyvale, CA, USA)

Measurement of ROS generation. ROS generation was detected using the DCFH-DA assay. Suspended HK-2 cells $\left(1 \times 10^{6}\right.$ cells/well $)$ were added to 6 -well plates, then treated with $10 \mu \mathrm{mol} / 1 \mathrm{DCFH}-\mathrm{DA}$ in serum-free DMEM/F-12 for $20 \mathrm{~min}$ at $37^{\circ} \mathrm{C}$. After two washes with PBS, cells were collected and resuspended at $1 \times 10^{6}$ cells $/ \mathrm{ml}$. DCF fluorescence was detected using a FACSCalibur flow cytometer (BD Biosciences, Franklin Lakes, NJ, USA) at an excitation wavelength of $488 \mathrm{~nm}$ and an emission wavelength of $535 \mathrm{~nm}$.

Annexin V apoptosis assay. The number of apoptotic cells was evaluated by flow cytometry using an FITC Annexin V Apoptosis Detection kit (BD Biosciences) according to the manufacturer's instructions. In brief, HK-2 cells were seeded in six-well plates at $2 \times 10^{5}$ cells per well and treated as described above. Cells were washed twice with PBS and re-suspended in $200 \mu \mathrm{l}$ binding buffer. After addition of $5 \mu \mathrm{l}$ Annexin V conjugate and incubation for $10 \mathrm{~min}$, the samples

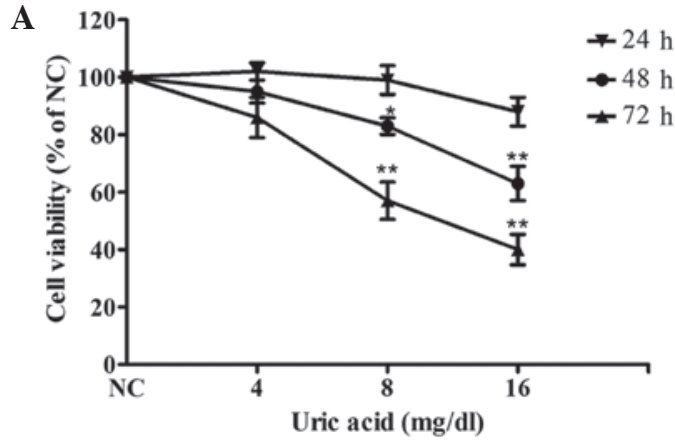

B

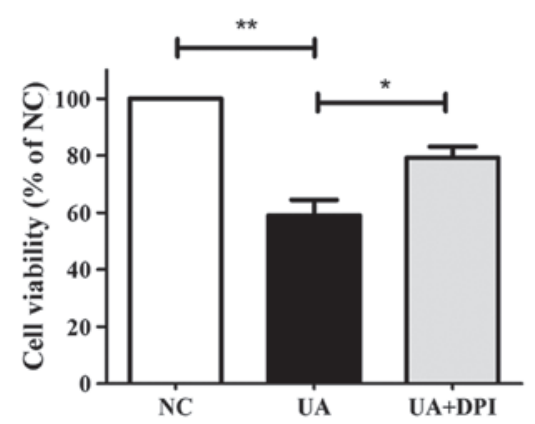

Figure 1. UA inhibits HK-2 cell viability. (A) Effect of UA on cell viability at various concentrations and times. (B) HK-2 cells were treated with $16 \mathrm{mg} / \mathrm{dl}$ $\mathrm{UA}$ for $48 \mathrm{~h}$ with or without the pre-treatment with nicotinamide adenine dinucleotide phosphate oxidase inhibitor DPI. Cell viability was determined using an MTT assay. Values are expressed as the mean \pm standard deviation. $n=3$, ${ }^{*} \mathrm{P}<0.05,{ }^{* *} \mathrm{P}<0.01$. UA, uric acid; NC, negative control; DPI, diphenylene iodonium.

were resuspended in $200 \mu \mathrm{l}$ binding buffer and $5 \mu \mathrm{l}$ propidium iodide (PI). The cells were examined using the FACSCalibur flow cytometer with ten thousand events collected for each sample.

Western blot analysis. HK-2 cells were added to 6-well plates at a density of $1 \times 10^{6}$ cells/well. Following serum starvation overnight, cells were co-cultured with UA $(4,8$ or $16 \mathrm{mg} / \mathrm{dl})$ for $48 \mathrm{~h}$. In the UA + DPI group, $10 \mu \mathrm{M}$ DPI was applied for $30 \mathrm{~min}$ prior to incubation with $16 \mathrm{mg} / \mathrm{dl}$ UA. Following two washes with PBS, cells were collected and centrifuged at $14,860 \mathrm{x}$ g for 5 minutes. With the supernatant removed, the cells were mixed with $80 \mu 1$ lysis buffer (Beyotime Institute of Biotechnology, Haimen, China). The lysate was incubated at $4^{\circ} \mathrm{C}$ for $15 \mathrm{~min}$ then centrifuged for $20 \mathrm{~min}$ at $20,800 \mathrm{x}$ g. The supernatant was collected and quantified for protein content using the BCA method. Equal amounts of total protein $(50 \mu \mathrm{g})$ were loaded and separated using $12 \%$ sodium dodecyl sulfate polyacrylamide gel electrophoresis then electrophoretically transferred onto a PVDF membrane. The membrane was incubated with primary antibodies (dilution, $1: 1,000)$ at $4^{\circ} \mathrm{C}$ overnight followed by incubation with secondary antibody (dilution, 1:5,000) at room temperature for $1 \mathrm{~h}$. Proteins were visualized by chemiluminescence using SuperECL Plus hypersensitivity luminous fluid. The bands were observed with a G:Box gel-imaging system (Syngene, Frederick, MD ,USA) $\beta$-actin was used as the internal control. The intensity of protein bands was quantified using Quantity One software (version 4.62; Bio-Rad Laboratories, Inc., Hercules, CA, USA). 

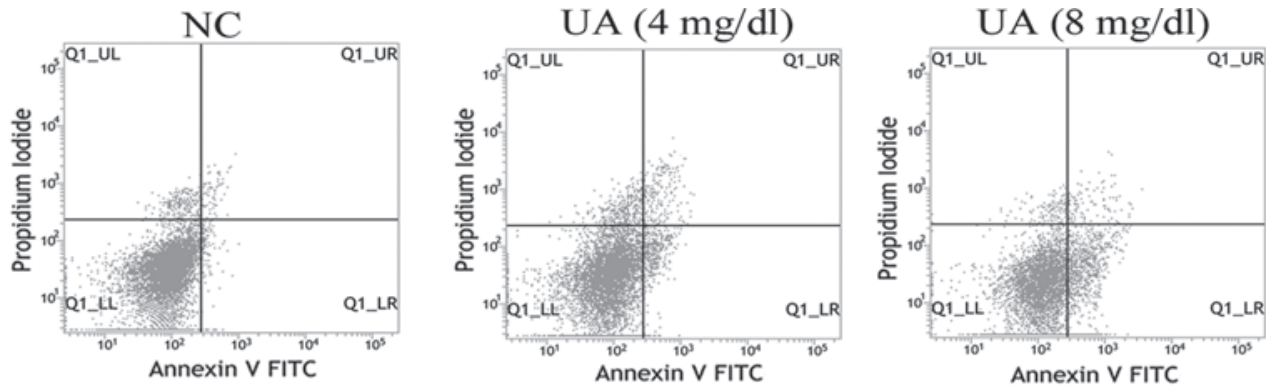

B

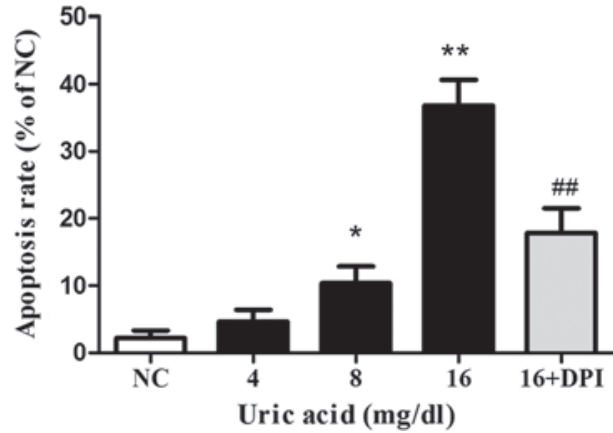

Figure 2. UA promotes HK-2 cell apoptosis. Cells were co-cultured with various doses of UA for $48 \mathrm{~h}$ with or without pre-treatment with DPI. (A) Flow cytometric dot plots. (B) Quantification of flow cytometry provided apoptotic rates. The cell populations in the right lower quadrant (Q1_LR) were considered as apoptotic. Apoptosis was induced by UA in a dose-dependent manner, which was prevented by the nicotinamide adenine dinucleotide phosphate oxidase inhibitor DPI. Values are expressed as the mean \pm standard deviation. The experiment was repeated 3 times and the image was representative of 3 separate experiments. ${ }^{*} \mathrm{P}<0.05,{ }^{* *} \mathrm{P}<0.01$ vs. NC; ${ }^{\# \#} \mathrm{P}<0.01$ vs. UA $(16 \mathrm{mg} / \mathrm{dl})$. UA, uric acid; NC, negative control; FITC, fluorescein isothiocyanate; DPI, diphenylene iodonium.

Statistical analysis. Statistical analysis was performed using SPSS software 18.0 (SPSS, Inc., Chicago, IL, USA). Values are expressed as the mean \pm standard deviation. Differences were assessed by Student's $t$-test or analysis of variance. $\mathrm{P}<0.05$ was considered to indicate a statistically significant difference.

\section{Results}

UA reduces kidney cell viability via Nox. To evaluate the effects of UA on cell viability, HK-2 cells were treated with $0,4,8$ or $16 \mathrm{mg} / \mathrm{dl} \mathrm{UA}$ for 24-72 $\mathrm{h}$ and subjected to an MTT assay. As shown in Fig. 1A, UA decreased HK-2 cell viability in a timeand dose-dependent manner. Treatment with $16 \mathrm{mg} / \mathrm{dl}$ UA for 48 and $72 \mathrm{~h}$ significantly reduced the number of viable cells to $63 \pm 6 \%$ and $40 \pm 5 \%$, respectively, of that of the control $(\mathrm{P}<0.01)$. Therefore, $16 \mathrm{mg} / \mathrm{dl} \mathrm{UA}$ for $48 \mathrm{~h}$ were determined as the ideal conditions for further assessing the involvement of Nox. As shown in Fig. 1B, Nox inhibition by pre-treatment with DPI (10 $\mu \mathrm{M}$ for $30 \mathrm{~min}$ ) significantly attenuated the cytotoxic effects of UA $(79 \pm 5.7 \%$ vs. $59 \pm 9.2 \%, \mathrm{P}<0.05)$.

UA promotes kidney cell apoptosis via Nox. To examine whether UA promotes apoptosis, HK-2 cells were incubated with various doses of UA for $48 \mathrm{~h}$ and subjected to flow cytometric analysis following Annexin V/PI double staining (Fig. 2). UA was found to concentration-dependently induce apoptosis in HK-2 cells, with $16 \mathrm{mg} / \mathrm{dl}$ UA producing an apoptotic rate of $36.8 \pm 4.4 \%$ compared with $2.2 \pm 0.8 \%$ in the $\mathrm{NC}$ group $(\mathrm{P}<0.01)$. In order to evaluate the involvement of Nox, HK-2 cells were incubated with DPI (10 $\mu \mathrm{M}$ for $30 \mathrm{~min})$ prior to treatment with $16 \mathrm{mg} / \mathrm{dl}$ UA for $48 \mathrm{~h}$. This Nox inhibition significantly inhibited the apoptotic effects of UA, as indicated
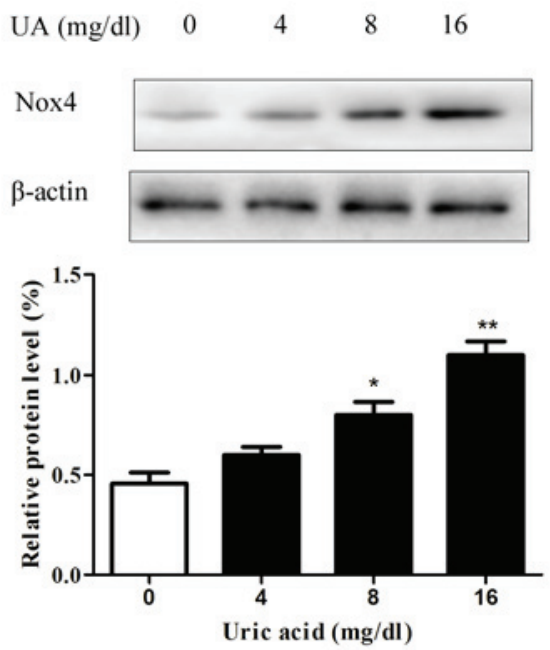

Figure 3. Expression of Nox4 in HK-2 cells. Cells were co-cultured with various doses of UA for $48 \mathrm{~h}$. $\beta$-actin was used as an internal reference. Values are expressed as the mean \pm standard deviation from at least three independent experiments. $\mathrm{n}=3,{ }^{*} \mathrm{P}<0.05,{ }^{*} \mathrm{P}<0.01$. Nox 4 , nicotinamide adenine dinucleotide phosphate oxidase 4; UA, uric acid.

by a reduction of the apoptotic rate to $17.9 \pm 3 \%(\mathrm{P}<0.01$ vs. UA at $16 \mathrm{mg} / \mathrm{dl})$.

UA upregulates the expression of Nox4 in HK-2 cells. Since the cytotoxic effects of UA on renal tubular cells were observed to be inhibited by DPI, it was indicated that UA exerts its effects via Nox. To examine the effects of UA on Nox, western blot analysis of Nox4, the predominant Nox in renal tubular cells, was performed. The results revealed that the protein levels of 
A

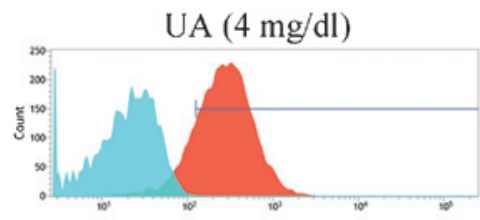

$\mathrm{UA}(16 \mathrm{mg} / \mathrm{dl})$

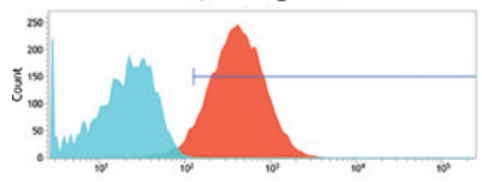

$\mathrm{NC}$

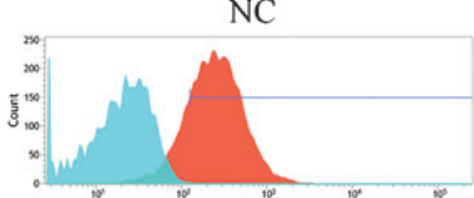

$\mathrm{UA}(8 \mathrm{mg} / \mathrm{dl})$

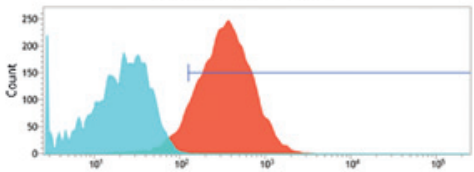

$\mathrm{UA}(16 \mathrm{mg} / \mathrm{dl})+\mathrm{DPI}$

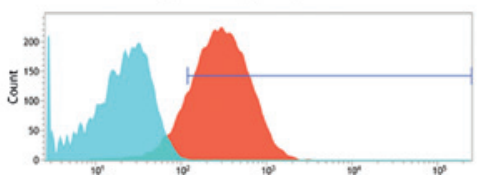

B

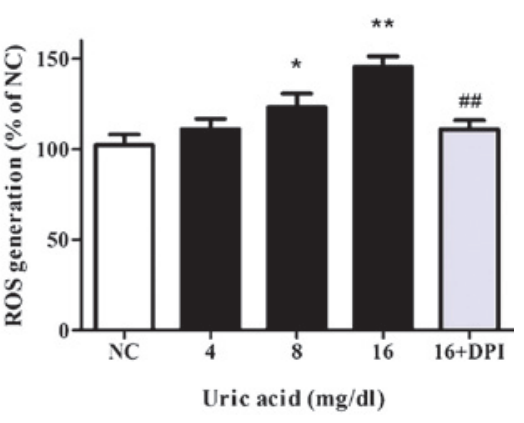

Figure 4. UA promotes the generation of ROS in HK-2 cells. Cells were treated with various concentrations of UA for $48 \mathrm{~h}$ with or without pre-treatment with DPI. (A) Flow cytometry was performed to measure ROS generation. The blue populations represent unstained cells (baseline control) and the red populations were cells stained by $2^{\prime}, 7^{\prime}$-dichlorodihydrofluorescein diacetate. The horizontal axis represents the mean fluorescence intensity of the cells and the vertical axis indicates the number of fluorescent cells. Compared to NC, the red peak gradually shifted to the right with increasing UA concentration, which was inhibited by nicotinamide adenine dinucleotide phosphate oxidase inhibitor DPI. (B) Quantification of flow cytometry analysis demonstrated that UA (8 and $16 \mathrm{mg} / \mathrm{dl}$ ) significantly enhanced intracellular ROS production, which was abrogated by DPI. The experiment was repeated 3 times and the images are representative of 3 separate experiments. Values are expressed as the mean \pm standard deviation. ${ }^{*} \mathrm{P}<0.05,{ }^{* *} \mathrm{P}<0.01 \mathrm{vs}$. NC; ${ }^{\# \#} \mathrm{P}<0.01 \mathrm{vs}$. UA (16 mg/dl). UA, uric acid; NC, negative control; DPI, diphenylene iodonium; ROS, reactive oxygen species.

A

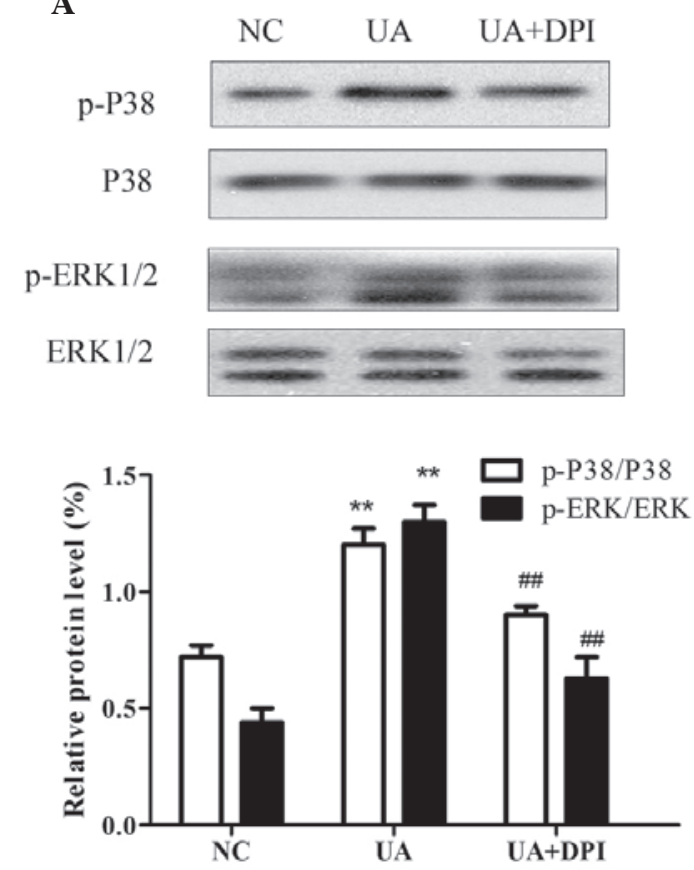

B
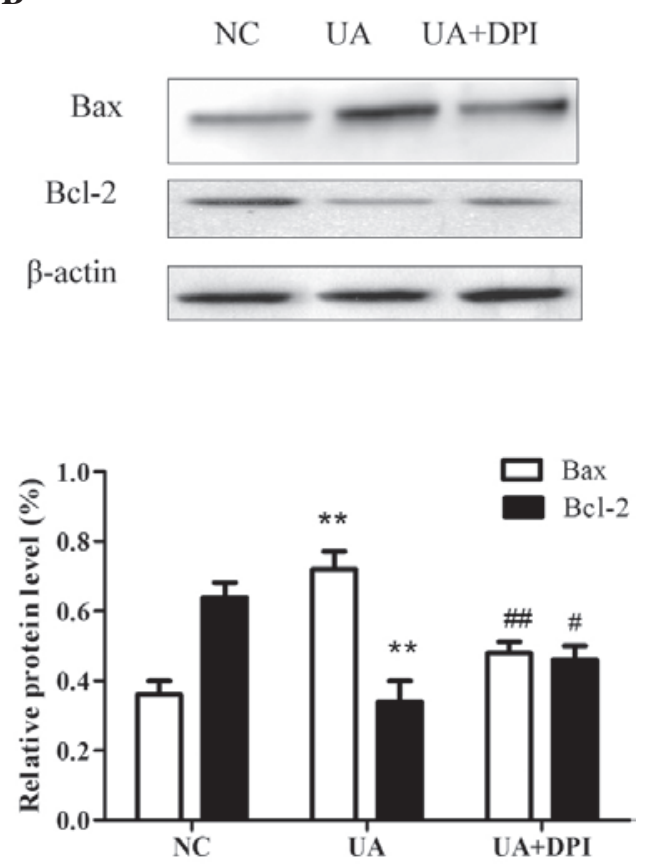

Figure 5. Western blot analysis of HK-2 cells revealed that UA (16 mg/dl for $48 \mathrm{~h}$ ) (A) significantly activated the phosphorylation of P38 and ERK1/2, which was inhibited by nicotinamide adenine dinucleotide phosphate oxidase inhibitor DPI and (B) induced apoptosis signaling by increasing Bax and decreasing Bcl-2, and that the balance of these apoptotic proteins was restored by DPI. GAPDH and $\beta$-actin were used as internal reference. Values are expressed as the mean \pm standard deviation from at least three independent experiments. $\mathrm{n}=3,{ }^{* *} \mathrm{P}<0.01$ vs. NC; ${ }^{*} \mathrm{P}<0.05$, ${ }^{\# \#} \mathrm{P}<0.01$ vs. UA. UA, uric acid; NC, negative control; p-ERK, phosphorylated extracellular signal-regulated kinase; Bcl-2, B-cell lymphoma 2; Bax, Bcl-2-associated X protein; GAPDH, glyceraldehyde-3-phosphate dehydrogenase.

Nox4 were upregulated by UA in a dose-dependent manner after incubation for $48 \mathrm{~h}$ (Fig. 3).

UA induces oxidative stress in HK-2 cells via Nox. As Nox4 is known to regulate ROS production $(7,8)$, the effects of UA on the levels of ROS in HK-2 cells were then assessed. Following treatment of cells with various concentrations of UA for $48 \mathrm{~h}$, ROS were detected by DCFH-DA staining and flow cytometric analysis. As demonstrated in Fig. 4A, the blue populations indicate the unstained cells (baseline control) and the red 
populations were cells stained by DCFH-DA. The horizontal axis presents the mean fluorescence intensity of the cells, which indicates the quantity of ROS generation, and the vertical axis presents the number of fluorescent cells, which was almost equal in each group. As demonstrated by the rightward-shift of the red peak, the generation of ROS was significantly enhanced by UA compared with control, reaching $145.7 \pm 4.3 \%$ at $16 \mathrm{mg} / \mathrm{dl} \mathrm{UA}(\mathrm{P}<0.01)$. Additionally, pretreatment with DPI significantly reduced the UA-induced elevation of ROS production $(110.9 \pm 5 \%)$ compared with $16 \mathrm{mg} / \mathrm{dl}$ UA treatment

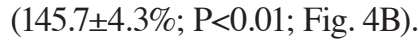

P38 and ERK1/2 signaling are involved in UA-induced apoptosis. It has been demonstrated that mitogen-activated protein kinase (MAPK) pathways are activated by upregulation of intracellular ROS (12-14). P38 and ERK1/2 are important members of the MAPK family, which regulates cell growth and apoptosis (15-17). The present study examined the effects of UA on the activation of P38 and ERK1/2 to investigate the possible mechanism of UA-induced apoptosis. As shown in Fig. 5A, the phosphorylation of P38 and ERK1/2 significantly increased following treatment of HK-2 cells with $16 \mathrm{mg} / \mathrm{dl}$ UA for $48 \mathrm{~h}$. Furthermore, inhibition of Nox with DPI attenuated the UA-induced phosphorylation of P38 and ERK1/2. These findings indicated UA treatment leads to the activation of P38/ERK signaling in kidney cells, possibly by upregulation of Nox4 expression and subsequent induction of ROS.

To investigate the underlying mechanisms of cell apoptosis, the effects of UA on the expression of Bcl-2 and Bax were assessed by western blot analysis. While UA treatment caused a significant increase in the protein levels of Bax and a decrease in Bcl-2 in $\mathrm{HK}-2$ cells, the Bcl-2/Bax balance was neutralized by pre-treatment with DPI (Fig. 5B).

\section{Discussion}

The present study revealed that UA treatment led to the upregulation of Nox 4 expression in HK-2 cells in a dose-dependent manner. Nox 4 then promoted the generation of ROS, leading to the induction of apoptosis. The phosphorylation of P38 and ERK1/2 and the imbalance of Bax/Bcl-2 were also demonstrated to be involved in this process. These results suggested that elevated UA promotes mitochondrial apoptosis through the P38/ERK pathway in renal tubular cells, which is induced by upregulation of Nox4 and production of ROS.

Uric acid is closely linked with chronic kidney disease (CKD) (18). In the pathophysiology of CKD, a decrease of the glomerular filtration rate increases the serum levels of UA, which in turn promote CKD progression (2); however, the underlying mechanisms have remained to be fully elucidated. UA has been demonstrated to trigger the upregulation of ROS in several cell types. ROS are able to regulate or induce multiple cellular processes, including epithelial-mesenchymal transition (19), growth (20), cell differentiation (21) and apoptosis $(7-9,13)$. The present study indicated that UA induced apoptosis in renal tubular cells by inducing ROS, which may cause cell loss and tubular dysfunction during the progression of CKD.

Of note, the present study demonstrated that the effects of UA were inhibited by DPI, which is indicative of the involvement of Nox. Nox has seven isoforms: Nox1, Nox2 (gp91phox), Nox3, Nox4, Nox5, Duox1 and Duox2 (22). In the kidney, Nox4 represents the predominant form and is abundantly expressed as a source of $\operatorname{ROS}(8,11,23)$. In tubular cells, Nox4 was shown to be upregulated by a variety of metabolic factors, including high glucose, angiotensin II and bilirubin $(19,24,25)$. The present study also confirmed that UA was able to promote the expression of Nox4 in a dose-dependent manner. This may be the primary origin of intracellular ROS.

Furthermore, the present study assessed the potential mechanisms of ROS-induced apoptosis. As is known, the MAPK family are key factors in numerous cellular processes. The main MAPKs are P38, ERK1/2 and c-Jun N-terminal kinase $1 / 2$, whose activity is stimulated by phosphorylation. The ROS-induced activation of MAPKs has been reported in several kidney diseases (26-28), while the association between UA and MAPKs has largely remained elusive; however, previous studies have indicated the participation of MAPKs in UA-induced tubular cell apoptosis $(29,30)$. As the underlying mechanisms required further elucidation, the present study examined the phosphorylation of P38 and ERK1/2 and found them significantly activated following exposure to UA. Furthermore, the present study revealed that pre-treatment with DPI was able to suppress the above effect, indicating that Nox4-derived ROS may be involved in the mechanism of UA-induced renal cell injury. In addition, the expression of Bax and Bcl-2, which can be regulated by MAPKs, was detected, revealing that high levels of UA caused a Bax/Bcl-2 imbalance, suggesting that apoptosis was induced through the mitochondrial pathway. A study by Verzola et al (30) also observed that UA promotes apoptosis in renal tubular cells by activating Nox4. Compared with this report, the present study provided further evidence to support their findings. Taken together, the crucial role of Nox4-ROS-MAPK pathway was clearly demonstrated by the current and previous studies.

In conclusion, the present study demonstrated that elevated UA promoted ROS-induced mitochondrial apoptosis by upregulating Nox4 expression in HK-2 cells. The mechanism was shown to involve the activation of P38 and ERK1/2. These findings provided a possible mechanism by which UA promotes the progression of chronic kidney disease. Furthermore, inhibition of Nox4 was demonstrated to prevent tubular cells from apoptosis and may therefore represent a therapeutic strategy chronic kidney disease.

\section{Acknowledgements}

This study was supported by the Science and Technology Development Program of Guangdong Province (no. 2012B031800081) and Young Teacher Foundation of Sun Yat-Sen University (no. 12ykpy31).

\section{References}

1. Obermayr RP, Temml C, Gutjahr G, Knechtelsdorfer M, Oberbauer R and Klauser-Braun R: Elevated uric acid increases the risk for kidney disease. J Am Soc Nephrol 19: 2407-2413, 2008.

2. Johnson RJ, Nakagawa T, Jalal D, Sánchez-Lozada LG, Kang DH and Ritz E: Uric acid and chronic kidney disease: Which is chasing which? Nephrol Dial Transplant 28: 2221-2228, 2013 
3. Jin M, Yang F, Yang I, Yin Y, Luo JJ, Wang H and Yang XF: Uric acid, hyperuricemia and vascular diseases. Front Biosci (Landmark Ed) 17: 656-669, 2012.

4. Convento MS, Pessoa E, Dalboni MA, Borges FT and Schor N: Pro-inflammatory and oxidative effects of noncrystalline uric acid in human mesangial cells: Contribution to hyperuricemic glomerular damage. Urol Res 39: 21-27, 2011.

5. Corry DB, Eslami P, Yamamoto K, Nyby MD, Makino H and Tuck ML: Uric acid stimulates vascular smooth muscle cell proliferation and oxidative stress via the vascular renin-angiotensin system. J Hypertens 26: 269-275, 2008.

6. Zhang JX, Zhang YP, Wu QN and Chen B: Uric acid induces oxidative stress via an activation of the renin-angiotensin system in 3T3-L1 adipocytes. Endocrine 48: 135-142, 2015.

7. Ago T, Kuroda J, Pain J, Fu C, Li H and Sadoshima J: Upregulation of Nox4 by hypertrophic stimuli promotes apoptosis and mitochondrial dysfunction in cardiac myocytes. Circ Res 106: $1253-1264,2010$

8. Sedeek M, Nasrallah R, Touyz RM and Hébert RL: NADPH oxidases, reactive oxygen species, and the kidney: Friend and foe. J Am Soc Nephrol 24: 1512-1518, 2013.

9. Brown DI and Griendling KK: Regulation of signal transduction by reactive oxygen species in the cardiovascular system. Circ Res 116: 531-549, 2015

10. Havasi A and Borkan SC: Apoptosis and acute kidney injury. Kidney Int 80: 29-40, 2011.

11. Sharma K: Obesity, oxidative stress, and fibrosis in chronic kidney disease. Kidney Int Suppl 4: 113-117, 2014.

12. Park J, Min JS, Kim B, Chae UB, Yun JW, Choi MS, Kong IK Chang KT and Lee DS: Mitochondrial ROS govern the LPS-induced pro-inflammatory response in microglia cells by regulating MAPK and NF-kB pathways. Neurosci Lett 584 191-196, 2015.

13. Zhao ZY, Luan P, Huang SX, Xiao SH, Zhao J, Zhang B, Gu BB Pi RB and Liu J: Edaravone protects HT22 neurons from $\mathrm{H} 2 \mathrm{O} 2$-induced apoptosis by inhibiting the MAPK signaling pathway. CNS Neurosci Ther 19: 163-169, 2013.

14. Changchien JJ, Chen YJ, Huang CH, Cheng TL, Lin SR and Chang LS: Quinacrine induces apoptosis in human leukemia K562 cells via p38 MAPK-elicited BCL2 down-regulation and suppression of ERK/c-Jun-mediated BCL2L1 expression. Toxicol Appl Pharmacol 284: 33-41, 2015.

15. Liu W, Ning R, Chen RN, Huang XF, Dai QS, Hu JH, Wang YW, Wu LL, Xiong J, Hu G, et al: Aspafilioside B induces G2/M cell cycle arrest and apoptosis by up-regulating $\mathrm{H}-\mathrm{R}$ as and N-Ras via ERK and p38 MAPK signaling pathways in human hepatoma HepG2 cells. Mol Carcinog: Feb 14, 2015 (Epub ahead of print).

16. Shi M, He X, Wei W, Wang J, Zhang T and Shen X: Tenascin-C induces resistance to apoptosis in pancreatic cancer cell through activation of ERK/NF-kB pathway. Apoptosis 20: 843-857, 2015.

17. Liu Y, Zhang S, Su D, Liu J, Cheng Y, Zou L, Li W and Jiang Y: Inhibiting (pro)renin receptor-mediated p38 MAPK signaling decreases hypoxia/reoxygenation-induced apoptosis in $\mathrm{H} 9 \mathrm{c} 2$ cells. Mol Cell Biochem 403: 267-276, 2015.
18. Boban M, Kocic G, Radenkovic S, Pavlovic R, Cvetkovic T, Deljanin-Ilic M, Ilic S, Bobana MD, Djindjic B, Stojanovic D, et al: Circulating purine compounds, uric acid, and xanthine oxidase/dehydrogenase relationship in essential hypertension and end stage renal disease. Ren Fail 36: 613-618, 2014.

19. He T, Guan X, Wang S, Xiao T, Yang K, Xu X, Wang J and Zhao J: Resveratrol prevents high glucose-induced epithelial-mesenchymal transition in renal tubular epithelial cells by inhibiting NADPH oxidase/ROS/ERK pathway. Mol Cell Endocrinol 402: 13-20, 2015.

20. Zhang Y, Yamamoto T, Hisatome I, Li Y, Cheng W, Sun N, Cai B, Huang T, Zhu Y, Li Z, et al: Uric acid induces oxidative stress and growth inhibition by activating adenosine monophosphate-activated protein kinase and extracellular signal-regulated kinase signal pathways in pancreatic $\beta$ cells Mol Cell Endocrinol 375: 89-96, 2013.

21. Mouche S, Mkaddem SB, Wang W, Katic M, Tseng YH, Carnesecchi S, Steger K, Foti M, Meier CA, Muzzin P, et al: Reduced expression of the NADPH oxidase NOX4 is a hallmark of adipocyte differentiation. Biochim Biophys Acta 1773: 1015-1027, 2007.

22. Kawahara T, Quinn MT and Lambeth JD: Molecular evolution of the reactive oxygen-generating NADPH oxidase (Nox/Duox) family of enzymes. BMC Evol Biol 7: 109, 2007.

23. Sedeek M, Callera G, Montezano A, Gutsol A, Heitz F, Szyndralewiez C, Page P, Kennedy CR, Burns KD, Touyz RM and Hébert RL: Critical role of Nox4-based NADPH oxidase in glucose-induced oxidative stress in the kidney: Implications in type 2 diabetic nephropathy. Am J Physiol Renal Physiol 299: F1348-F1358, 2010.

24. Kim SM, Kim YG, Jeong KH, et al: Angiotensin II-induced mitochondrial Nox4 is a major endogenous source of oxidative stress in kidney tubular cells. PLoS One 7: e39739, 2012.

25. Oh SW, Lee ES, Kim S, Na KY, Chae DW, Kim S and Chin HJ: Bilirubin attenuates the renal tubular injury by inhibition of oxidative stress and apoptosis. BMC Nephrol 14: 105, 2013.

26. Qi W, Niu J, Qin Q, Qiao Z and Gu Y: Glycated albumin triggers fibrosis and apoptosis via an NADPH oxidase/Nox4-MAPK pathway-dependent mechanism in renal proximal tubular cells. Mol Cell Endocrinol 405: 74-83, 2015.

27. Gao X, Wu J, Qian Y, et al: Oxidized high-density lipoprotein impairs the function of human renal proximal tubule epithelial cells through CD36. Int J Mol Med 34: 564-572, 2014.

28. Jaiman S, Sharma AK, Singh K and Khanna D: Signalling mechanisms involved in renal pathological changes during cisplatin-induced nephropathy. Eur J Clin Pharmacol 69: 1863-1874, 2013

29. Quan H, Peng X, Liu S, Bo F, Yang L, Huang Z, Li H, Chen X and Di W: Differentially expressed protein profile of renal tubule cell stimulated by elevated uric acid using SILAC coupled to LC-MS. Cell Physiol Biochem 27: 91-98, 2011.

30. Verzola D, Ratto E, Villaggio B, Parodi EL, Pontremoli R, Garibotto G and Viazzi F: Uric acid promotes apoptosis in human proximal tubule cells by oxidative stress and the activation of NADPH oxidase NOX 4. PLoS One 9: e115210, 2014 